\title{
Fundamental Decomposition Analysis of Chemically Amplified Molecular Resist for below $22 \mathrm{~nm}$ Resolution
}

\author{
Daiju Shiono, Hideo Hada, Kazufumi Sato, Yasuyuki Fukushima*, \\ Takeo Watanabe* and Hiroo Kinoshita* \\ Tokyo Ohka Kogyo Co., Ltd., \\ 1590 Tabata, Samukawa, Kanagawa, 253-0114, Japan \\ * LASTI, University of Hyogo \\ 3-1-2, Kouto, Kamigoori, Akou, Hyogo, 678-1205, Japan
}

\begin{abstract}
Molecular resists of Prot-2 and Prot-1 were synthesized for decomposition analysis and lithographic evaluation. After checking their structure, purity and thermal property, decomposition behavior was analyzed by high performance liquid chromatography (HPLC). From the analysis, it was found that the main reaction in an exposed area was the deprotection reaction of the protecting group in electron beam (EB) and extreme ultraviolet (EUV) lithography. The exposure dose at which the conspicuous deprotection reaction occurs coincides with the exposure dose at which the resist film thickness reduces. Furthermore, the resists which include completely deprotected group, partially deprotected group and completely protected group, which dissolution rates were different coexist at the boundary between an exposed and an unexposed region. The fundamental decomposition-analysis results indicate that the line edge roughness (LER) is caused by the existence of the different dissolution rates of resist component materials at the boundary between an exposed and an unexposed region. After confirming the fundamental analysis, these molecular resists were evaluated on a lithographic performance by EB lithography. Resist-A consisting of Prot-1 showed $20 \mathrm{~nm} \mathrm{hp}$ resolution at the exposure dose of $36 \mu \mathrm{C} / \mathrm{cm}^{2}$. In this paper, we will discuss about the resolution and the LER property of molecular resists at the point of their decomposition behavior.
\end{abstract}

Keyword: chemically amplified positive tone, Electron beam lithography, molecular resist, decomposition analysis, EUV resist

\section{Introduction}

To meet the growing demands of the semiconductor industry, new process techniques and resist materials have been developed. Extreme ultraviolet (EUV) and electron beam (EB) lithography are emerging the next generation technologies for a pattern fabrication at $22 \mathrm{~nm}$ and beyond. For the 22 $\mathrm{nm}$ node, the high resolution and the low line width roughness (LWR) should be achieved simultaneously." Non chemically amplified positive- and negative-tone resists have been reported using 1,3,5-tris[4-(4-toluenesulfonyloxy)phenyl]-benzene (TsOTPB) and 4,4',4"-tris(allylsuccinimido)-triphenylamine (ASITPA), respectively. ${ }^{2)}$ Recently, many researchers have reported on molecular resist materials to improve the line width roughness and the resolution because their molecular size is smaller than that of the polymeric materials. $^{3-10)}$ The surface roughness of a molecular resist is smaller than that of a polymeric material. ${ }^{11-12)}$ For the LWR reduction, it is reported that controlling the 
distribution of a protecting group on a molecular resist material is an effective method, which leads to controlling reactions of a chemically amplified (CA) reaction in a resist film. ${ }^{13-16)}$ It is also reported that low-molecular-weight polymeric materials showed good resolution and LWR. ${ }^{17)}$ It is reported that chemically amplified reactions at the image boundary between an exposed and a unexposed area are an important factor for reducing the LER of resist patterns in EUV and EB lithography. ${ }^{18)}$

In this report, we analyze the decomposition behavior before and after exposure and discuss the resolution and the roughness of a molecular resist.

\section{Experimental}

2.1. Materials and analyses

${ }^{1} \mathrm{H}$ nuclear magnetic resonance (NMR) spectra were obtained in deuterated dimethyl sulfoxide $\left(\right.$ DMSO- $d_{6}$ ) with tetramethylsilane (TMS) as an internal standard using a JEOL AL-400 $(400 \mathrm{MHz})$ spectrometer. Infrared (IR) spectra were recorded using a Perkin-Elmer 2000 spectrometer. Decomposition analysis was carried out using a high-performance liquid chromatography (HPLC) analyzer (Shimadzu, SCL-10AVP).

\subsubsection{Synthesis of CA1}

1-Ethyl-3-(3-dimethylaminopropyl)-carbodiimid ehydrochloride ( $7.0 \mathrm{~g}, 37 \mathrm{mmol})$, 1-hydroxymethyl adamantane $(5.0 \mathrm{~g}, 30 \mathrm{mmol})$, and a carboxylic acid derivative of CA2 (27.6 g, $33 \mathrm{mmol})$, which was synthesized by acid condensation from a phenolic compound, ${ }^{19)}$ were dissolved in dry tetrahydrofuran $(300 \mathrm{~mL})$ in a nitrogen atmosphere. After a clear solution was formed, dimethylaminopyridine (DMAP; $0.12 \mathrm{~g}, 1.0 \mathrm{mmol}$ ) was added to a solution at a temperature of $0{ }^{\circ} \mathrm{C}$. After stirring for $10 \mathrm{~h}$, the reaction was quenched with water. The mixture was concentrated and ethyl acetate was added. The mixture was extracted three times using ethyl acetate. After concentration of the ethyl acetate solution, the mixture was purified by column chromatography on silica gel. Finally, a yellow powder of the carboxylic acid derivative of CAl was obtained after drying in vacuum (13 g, yield $40 \%$ ). The purity of the product was $99.0 \%$ as analyzed by HPLC. The molecular structure is shown in Fig. 1.

IR: $3386(\mathrm{COOH}), 2905(\mathrm{CH}), 2850(\mathrm{CH}), 1737$ $(\mathrm{C}=\mathrm{O})$, and $1285 \mathrm{~cm}^{-1}(\mathrm{Ar})$; ${ }^{1} \mathrm{H}-\mathrm{NMR} \delta 12.83$ brs $1 \mathrm{H}, 8.85 \mathrm{~s} 4 \mathrm{H}, 6.32-6.78 \mathrm{~m} 14 \mathrm{H}, 5.82 \mathrm{~d} 2 \mathrm{H}$,
$4.62 \mathrm{~s} 4 \mathrm{H}, 4.46 \mathrm{~s} 2 \mathrm{H}, 3.71 \mathrm{~s} 2 \mathrm{H}, 3.57 \mathrm{~s} 2 \mathrm{H}, 1.96 \mathrm{~s}$ $12 \mathrm{H}, 1.89 \mathrm{~s} 3 \mathrm{H}, 1.85 \mathrm{~s} 12 \mathrm{H}, 1.43-1.66 \mathrm{~m} 12 \mathrm{H}$.

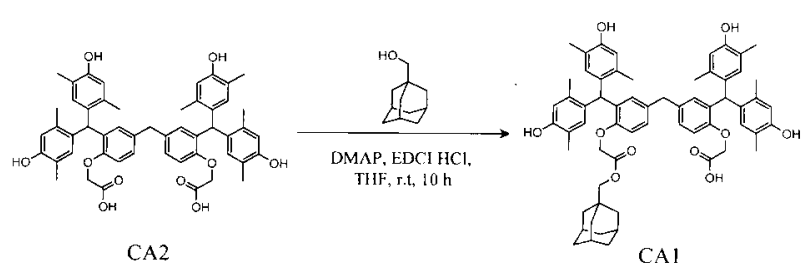

Fig. 1. Synthesis of CAl

\subsubsection{Synthesis of Prot-2}

Carboxylic acid derivative of CA2 (40.00 g, $48.49 \mathrm{mmol})$ and 2-methyl-2-adamantyl bromoacetate $(27.85 \mathrm{~g}, 96.98 \mathrm{mmol})$ were dissolved in dry tetrahydrofuran $(200 \mathrm{~mL})$ in a nitrogen atmosphere. After forming a clear solution, triethyl amine $(15.20 \mathrm{~g}, 150.21 \mathrm{mmol})$ was added dropwise, and a white precipitate gradually formed. After stirring for $10 \mathrm{~h}$, the reaction was quenched with water. The mixture was concentrated and ethyl acetate was added. The mixture was extracted using ethyl acetate three times. Finally, a yellow powder of prot-2, which has only two protecting groups per molecule, was obtained after drying in vacuo (42.02 g, $33.92 \mathrm{mmol}$, yield: $84.8 \%$ ). The chemical structure is shown in Fig. 2.

IR: $3417,2920,2863,1750,1728,1495,1292$, and $1278 \mathrm{~cm}^{-1}$; ${ }^{1} \mathrm{H}$ NMR $(400 \mathrm{MHz}): 8.80(4 \mathrm{H}$, brs), 6.23-6.94 (14H, m), $5.84(2 \mathrm{H}, \mathrm{s}), 4.68(8 \mathrm{H}, \mathrm{s})$, $3.58(2 \mathrm{H}, \mathrm{s}), 1.39-2.19(58 \mathrm{H}, \mathrm{m})$.

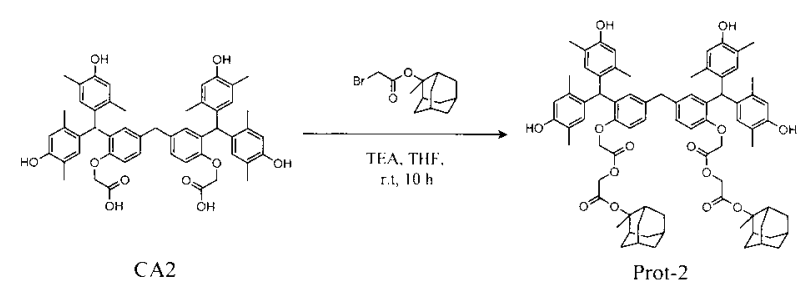

Fig. 2. Synthesis of Prot-2

\subsubsection{Synthesis of Prot-1}

CA1 $(2.2 \quad \mathrm{~g}, \quad 2.3 \mathrm{mmol})$ and 2-methyl-2-adamantyl bromoacetate $(0.72 \mathrm{~g}, 2.5$ $\mathrm{mmol})$ were dissolved in dry tetrahydrofuran (20 $\mathrm{mL}$ ) in a nitrogen atmosphere. After forming a clear solution, triethyl amine $(0.40 \mathrm{~g}, 4.0 \mathrm{mmol})$ was added, and a white precipitate gradually formed. After stirring for $10 \mathrm{~h}$, the reaction was quenched with water. The mixture was concentrated and ethyl acetate was added. The mixture was extracted using ethyl acetate by three times. Finally, a yellow powder of Prot-1 was 
obtained after drying in vacuum $(2.3 \mathrm{~g}$, yield: $85 \%)$. The chemical structure of Prot-1 is shown in Fig. 3.

IR: $3361(\mathrm{OH}), 2907(\mathrm{CH}), 2851(\mathrm{CH}) 1743$ $(\mathrm{C}=\mathrm{O})$ and $1286 \mathrm{~cm}^{-1}(\mathrm{Ar}) ;{ }^{1} \mathrm{H}-\mathrm{NMR} \delta 8.85 \mathrm{~s}$ $4 \mathrm{H}, 6.30-6.85 \mathrm{~m} \mathrm{14H}, 5.84 \mathrm{~s} 2 \mathrm{H}, 4.69 \mathrm{~s} 2 \mathrm{H}, 4.68 \mathrm{~s}$ $2 \mathrm{H}, 4.63$ s $2 \mathrm{H}, 3.73$ s $2 \mathrm{H}, 3.59$ s $2 \mathrm{H}, 1.98$ s $12 \mathrm{H}$, $1.88 \mathrm{~s} 12 \mathrm{H}, 1.38-2.23 \mathrm{~m} 32 \mathrm{H}$.

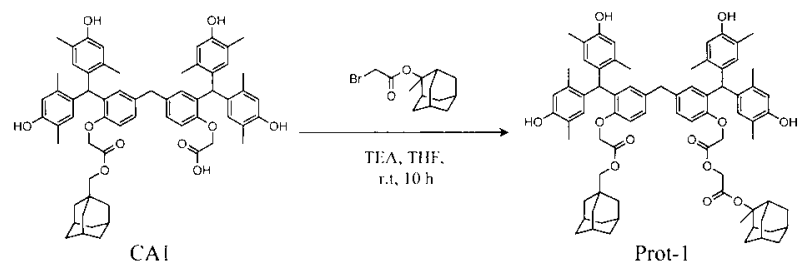

Fig. 3. Synthesis of Prot-1

\subsubsection{Synthesis of PHS-prot}

Poly (hydroxystyrene) (PHS, $30.0 \mathrm{~g}$ ) and sodium hydride ( $4.4 \mathrm{~g}, 60 \%$ in mineral oil) were dissolved in dry tetrahydrofuran $(250 \mathrm{~mL})$ in a nitrogen atmosphere. After stirring for $10 \mathrm{~min}$ at a temperature of $0 \quad{ }^{\circ} \mathrm{C}$, 2-methyl-2-adamantyl bromoacetate $(28.7 \mathrm{~g}, 100 \mathrm{mmol})$ was added at room temperature. After stirring for $10 \mathrm{~h}$, the reaction was quenched with water. The mixture was concentrated and ethyl acetate was added. The mixture was extracted three times using ethyl acetate. After concentration, the polymer was washed with heptane and filtrated. Finally, a yellow powder of PHS-prot was obtained after drying in vacuum $(43.0 \mathrm{~g})$. The molecular structure of PHS-prot-mad is shown in Fig. 4.

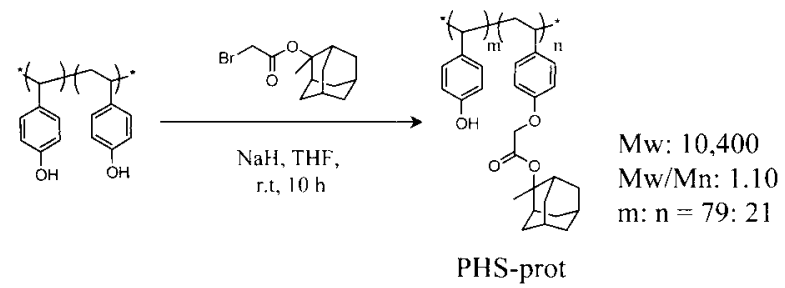

Fig. 4. Synthesis of PHS-prot

\subsection{Resist sample preparation}

To evaluate lithographic property, resist samples formulated with each molecular resist material, a photo acid generator (PAG), a quencher, and a casting solvent were prepared. Triphenylsulfonium perfluoro-1-butanesulfonate (TPS-PFBS) and trioctylamine (TOA) were used as the PAG and quencher, respectively. The casting solvent was a mixture of propylene glycol monomethylether acetate (PGMEA) and propylene glycol monomethylether (PGME). The details of the resist formulations are described in Table 1.

Table 1. Resist sample formulation

\begin{tabular}{ccccc} 
No. & Resist sample & Material & PAG & quencher \\
\hline 1 & Resist A & Prot-2 & TPS-PFBS & - \\
2 & Resist B & Prot-2 & TPS-PFBS & trioctylamine \\
3 & Resist C & Prot-1 & TPS-PFBS & trioctylamine \\
4 & Resist D & PHS-prot & TPS-PFBS & trioctylamine \\
\hline
\end{tabular}

2.3 Decomposition analysis of molecular resists

The samples of molecular resists was spin-coated on silicon wafers and heated on a hot plate at a temperature of $110^{\circ} \mathrm{C}$ for $90 \mathrm{~s}$. The film thickness of each resist sample was measured using a multiwavelength interference thickness measurement tool (Nanospec model 6100A). The EB exposure was carried out using a Hitachi HL-800D EB direct writing tool with an acceleration voltage of $70 \mathrm{kV}$ connected to a coater/developer in-line system. After EB exposure dose of $E_{0}$ value and post exposure bake (PEB), a resist film was scratched out and analyzed by HPLC.

2.4 Thermal property measurement of each molecular resist film

A temperature of resist film surface starting to soften up was measured by using an E-sweep (SII NanoTechnology). If the temperature starting to soften up of the resist film is lower than the post-exposure bake (PEB) temperature, the lithographic property such as the ultimate resolution degrades. To evaluate thermal property, the resists, which included Prot-2, Prot-1, Deprot-1, and Deprot-2, were determined in the liquid chromatography analysis after the acid deprotection reactions of Prot-2 and Prot-1. They were spin-coated on a silicon wafer and heated on a hot plate at a temperature of $110{ }^{\circ} \mathrm{C}$ for $90 \mathrm{~s}$, respectively. Film thickness of all the samples was $50 \mathrm{~nm}$. The film thickness of each resis sample was measured using a multiwavelength interference thickness measurement tool (Nanospec model 6100A).

In addition, since the interaction between AFM cantilever and resist surface increases if a resist 
soften, a resist soften temperature can be determined by a torsion signal which started to increase utilizing an atomic force microscopy (AFM) when increasing a heated temperature of a resist.

\subsection{Surface roughness measurement}

The resist sample films were prepared in the same manner as described in \$2.2. After EB exposure, the resist films were heated at a temperature of $100^{\circ} \mathrm{C}$ for $90 \mathrm{~s}$ and were developed using a developer (NMD-3 $2.38 \mathrm{wt} \%$, Tokyo Ohka Kogyo) of $0.26 \mathrm{~N}$ TMAH at a temperature of $23{ }^{\circ} \mathrm{C}$. After the development, the surface roughness of the resist film was measured by an atomic force microscopy (AFM).

\subsection{Lithographic performance evaluations}

To investigate the lithographic performance of molecular resist, EB lithographic evaluation was carried out by an EB writing system (ELS7500, Elionix Inc.), which has a acceleration voltage of $50 \mathrm{kV}$. The sample films were spin-coated on a silicon wafer and heated on a hot plate at a temperature of $110^{\circ} \mathrm{C}$ for $90 \mathrm{~s}$. After the EB exposure, the resist films were baked at a temperature of $90^{\circ} \mathrm{C}$ for $90 \mathrm{~s}$ for $\mathrm{PEB}$ and developed in NMD-3 2.38 wt $\%$ (Tokyo Ohka Kogyo) aqueous $0.26 \mathrm{~N}$ tetramethylammonium hydroxide (TMAH) at a temperature of $23^{\circ} \mathrm{C}$. The dose of $E_{\text {size }}$ was determined to be an exposure dose when the feature size of $50 \mathrm{~nm}$ (lines/spaces=1/1) was achieved. The top-view of the fabricated pattern was observed by a scanning electron microscope (SEM), Hitachi S-9220.

\section{Results and Discussion}

3.1 Decomposition analysis of Resists A and B

Figure 5 shows the sensitivity curves of resists $A$ and $\mathrm{B}$. Resist A exhibited high sensitivity. Resist $\mathrm{B}$ exhibited good contrast. The $\mathrm{E}_{0}$ values of resists $A$ and B were 2.5 and $20 \mu \mathrm{C} / \mathrm{cm}^{2}$, respectively.

Figure 6. shows an example of HPLC charts of resist $A$ after EB exposure and $\mathrm{PEB}$. It can be observed that the main decomposition reaction was the deprotection reaction of prot-2. The production evidence of deprot-1-prot-1 and deprot-2 was confirmed by determining the retention time of each preparation.

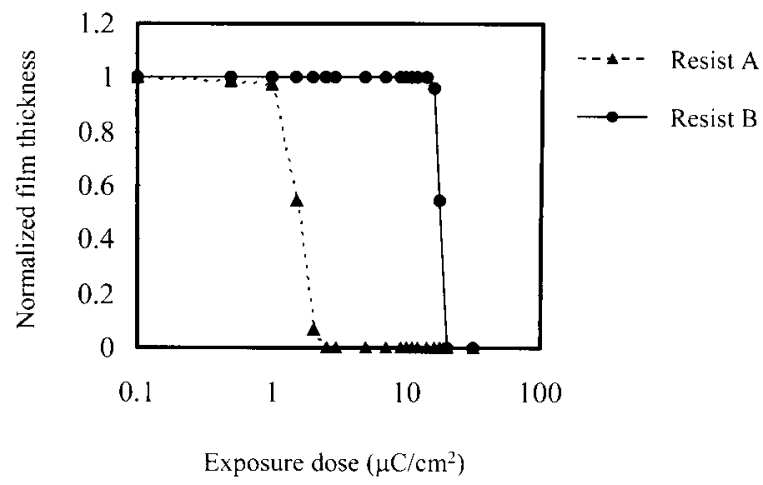

Fig. 5. Contrast curves of Resist A and B

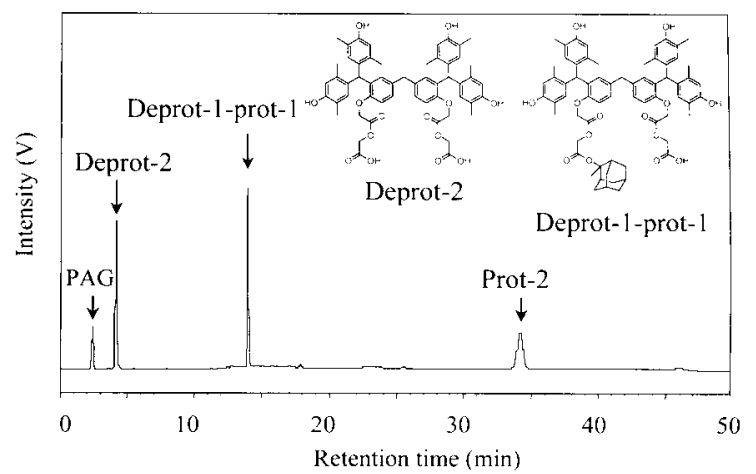

Fig. 6. An HPLC chart of Resist A after EB exposure and PEB

Figure 7 shows the area percentages, which mean the concentration percentages of HPLC area for Prot-2, Deprot-1-prot-1, and Deprot-2 for each EB exposure dose. As shown in Fig. 7a, the deprotection reaction occurs gradually in resist $A$ at a high EB exposure dose. However, as shown in Fig. $7 \mathrm{~b}$, the deprotection of resist $\mathrm{B}$ barely occurs at a EB exposure dose below $10 \mu \mathrm{C} / \mathrm{cm}^{2}$. It is considered that trioctylamine acts as a quencher, which prevents the deprotection reaction at a $\mathrm{EB}$ exposure dose below $10 \mu \mathrm{C} / \mathrm{cm}^{2}$. As shown in Figs. 5 and 7 , resist film thickness changes as the deprotection reaction proceeds. The area percentage of HPLC area of Prot-2 was lower than $50 \%$ at an exposure dose of $\mathrm{E}_{0}$. As shown in Fig. 7, the percentage of HPLC area of Deprot-1-prot-1 reaches a maximum value around exposure dose of $\mathrm{E}_{0}$, and then the area percentage decreases. The area percentage of Deprot-2 increases as an exposure dose increases. From the deprotection behavior of Prot-2 shown in Fig. 7, it is considered that Deprot-2 is generated from Deprot-1-prot-1 in a stepwise manner. 

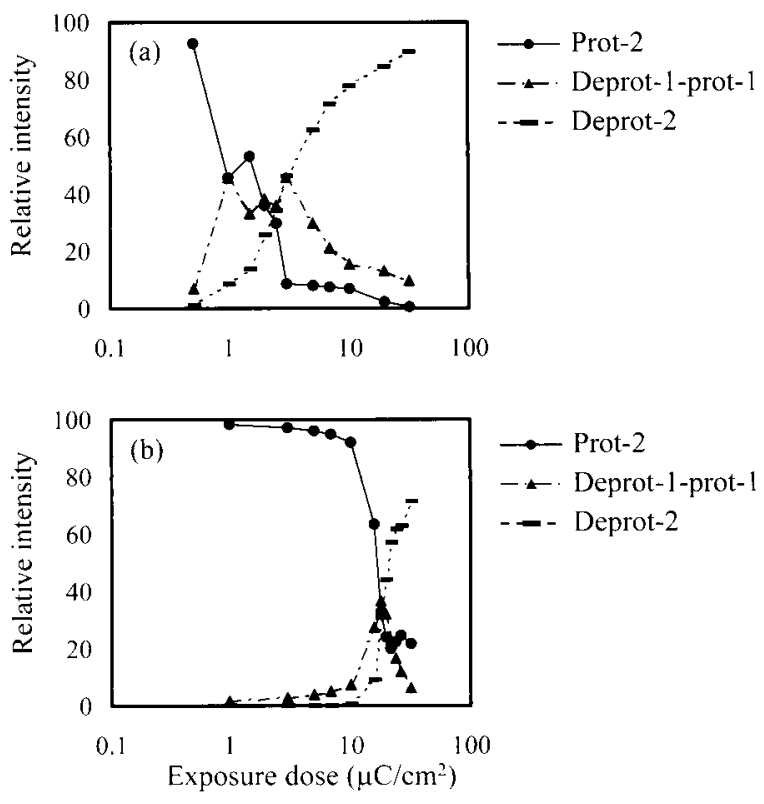

Fig. 7. Area percentages of prot-mad-2, deprot-1-prot-mad-1, and deprot-2 by using HPLC; (a) after EB exposure and PEB of Resist $A$, and (b) after $\mathrm{EB}$ exposure and $\mathrm{PEB}$ of Resist $\mathrm{B}$

The dissolution rates of Prot-2, Deprot-1-prot-1 and Deprot-2 were measured for several concentrations of TMAH employed as a developer. The fastest dissolution rate was that of Deprot-2, with a rate of $1233 \mathrm{~nm} / \mathrm{s}$ at a concentration of 1.19 $w t \%$ of TMAH solution as shown in Fig. 8. The rate of Prot- 2 was almost $0 \mathrm{~nm} / \mathrm{s}$ for each TMAH concentration. The differences in dissolution rate of Prot-2, Deprot-1-prot-1, and Deprot-2 were confirmed.

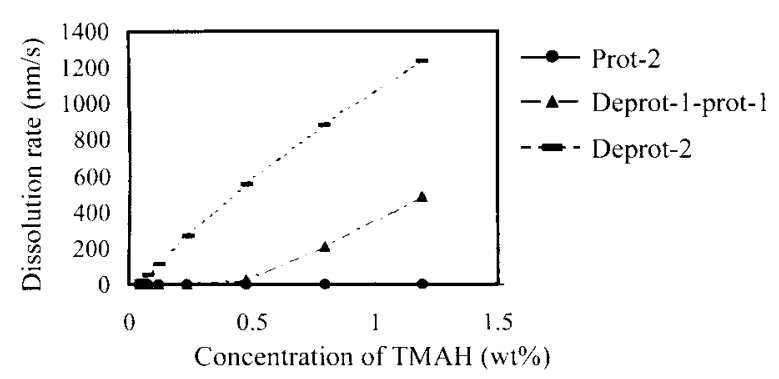

Fig. 8. Dissolution rates of Prot-2, Deprot-1-prot-1, and Deprot-2 at each TMAH concentration

\subsection{Decomposition analysis of Resist C}

Figure 9 shows the contrast curve for Resist C including Prot-1, which has just one protecting group per molecule. The $\mathrm{E}_{0}$ value of resist $\mathrm{C}$ was $24 \mu \mathrm{C} / \mathrm{cm}^{2}$

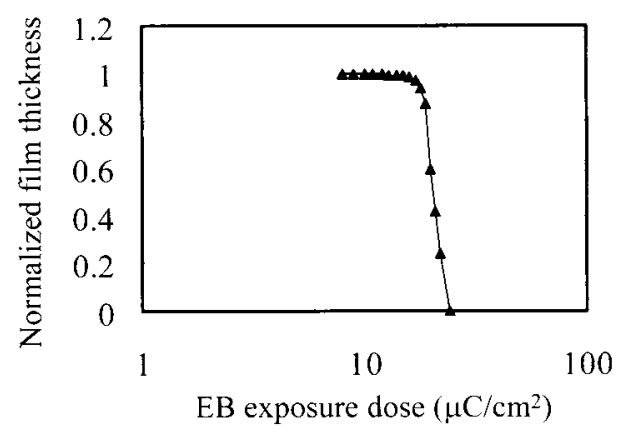

Fig. 9. Contrast curve of resist C

Figure 10 shows the results of HPLC analysis of resist $\mathrm{C}$ after $\mathrm{EB}$ exposure and after PEB for each exposure dose. The area percentage of Prot-1 obtained by HPLC decreased markedly over the exposure dose of $10 \mu \mathrm{C} / \mathrm{cm}^{2}$, while the percentage of HPLC area of deprot-1 increased. The exposure dose at which the marked deprotection reaction occurs coincides with the exposure dose at which the resist film thickness reduces, as shown in the contrast curves of Figs. 9 and 10. At the $\mathrm{E}_{0}$ of resist $\mathrm{C}$, concentration of Deprot-1 became higher than that of Prot-1. On the other hand, the film thickness loss of resist $\mathrm{C}$ was not observed when Prot-1 existed as major component at an exposure dose below $10 \mu \mathrm{C} / \mathrm{cm}^{2}$. From the HPLC analysis, it was found that dissolution switching of resist $\mathrm{C}$ occurs when Prot- 1 is employed at a level of one protecting group per molecule.

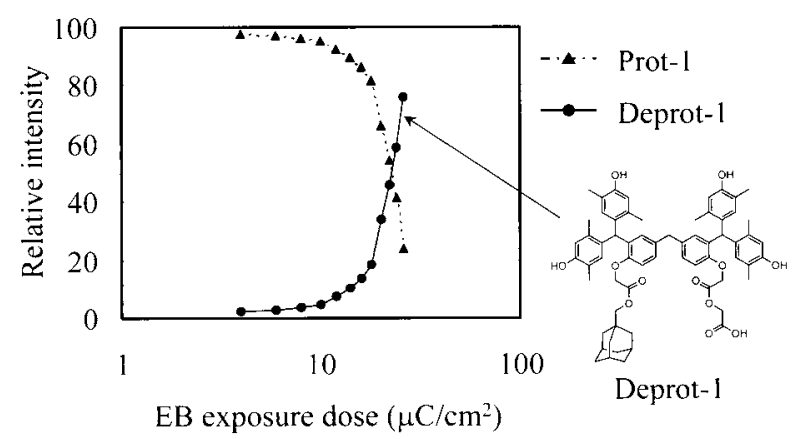

Fig. 10. Area percentages of Prot-1 and Deprot-1 of resist $\mathrm{C}$ after $\mathrm{EB}$ exposure and PEB measure by HPLC

3.3 Thermal property of each molecular resist film

Figure 11 shows the heat temperature dependency of the torsion of each molecular resist material including Prot-2, Prot-1, Deprot-1 and Deprot-2. It is reported that the thermal flow temperature of a resist pattern has a relation to the acid diffusion coefficient of an 
exposed area, which will play an important role to increasing the resolution. ${ }^{20)}$

No significant torsion signal change was observed at a lower temperature of $100{ }^{\circ} \mathrm{C}$ in all samples. The resists, which included Prot- 1 and Prot-2 started to soften at a temperature of approximately $140^{\circ} \mathrm{C}$. The resists, which included Deprot-1 and Deprot-2 started to soften at a temperature of approximately $160^{\circ} \mathrm{C}$. As results, the drastic thermal degradation by the deprotection reaction would not occur using Prot-1 and Prot-2. Furthermore, the temperature starting to soften up of resist material species including the deprotected compound is higher than process conditions for resist patterning.
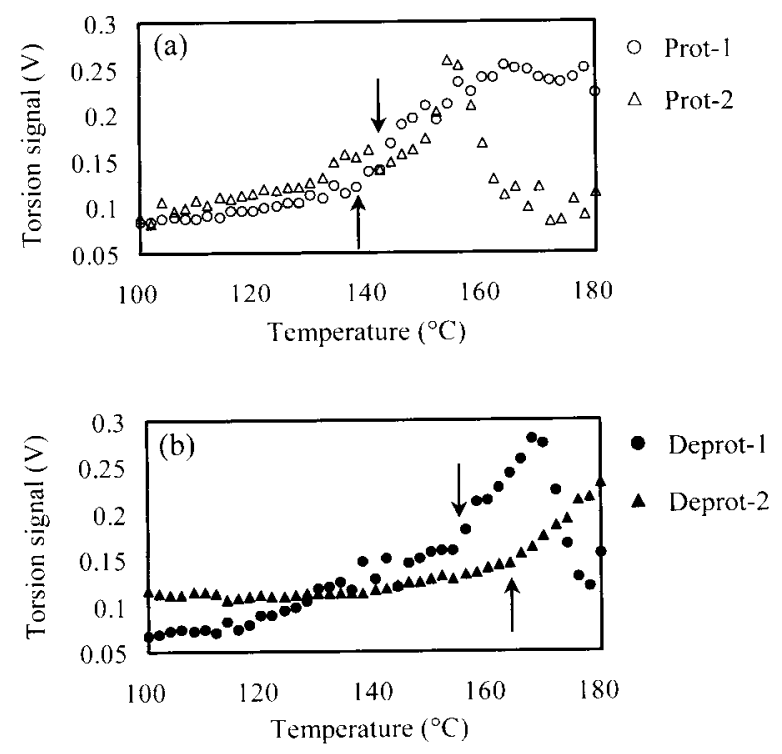

Fig. 11. Temperature dependency of the torsion of each molecular resist material

(a) Torsion signal of Prot-1 and Prot-2

(b) Torsion signal of Deprot-1 and Deprot-2

\subsection{Surface roughness evaluation}

The surface roughness of the resist samples after development for each EB exposure dose was measured by AFM to estimate the roughness property for each material as shown in Fig. 12. The surface roughness of all the samples increases as the dose increases and reaches the maximum surface roughness at each exposure dose of $E_{0}$. Molecular resist $\mathrm{C}$ showed the smallest maximum surface roughness in three resist samples. We consider that the smaller component of a molecular resist is effective for a roughness improvement compared to polymeric sample of resist $D$. Furthermore, resist $\mathrm{C}$ has just two variations in dissolution of Prot-1 and Deprot-1 after exposure and $\mathrm{PEB}$, while resist $\mathrm{B}$ including Prot- 2 has three variations in dissolution including two deprotected materials. Thus, resist $\mathrm{C}$ has the potential to improve a roughness property because of its controlled dissolution rate of an exposed area as well as its smaller molecular size in comparison with that of a polymeric material. As results, it is confirmed that reducing the variation in dissolution due to protected and deprotected materials of an exposed area is significant factor to reduce the LER.

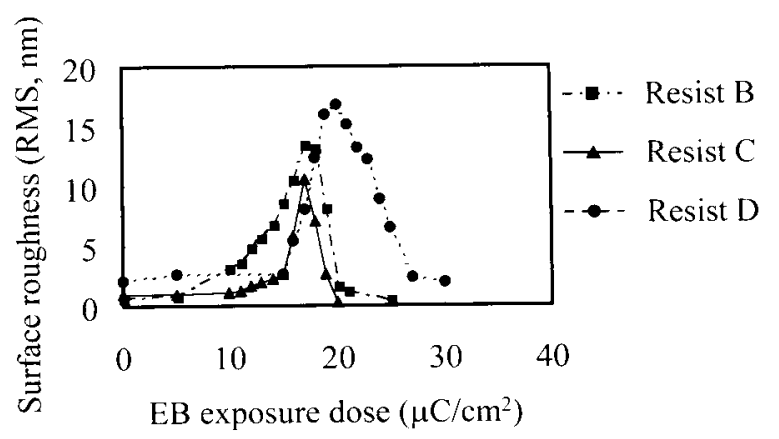

Fig. 12. Exposure dose dependency of the surface roughness for each resist

\subsection{Lithographic evaluation}

The lithographic performance of these resist samples was evaluated using EB lithography. SEM images of a line and space pattern are shown in Fig. 13. Molecular resists $\mathrm{B}$ and $\mathrm{C}$ showed better resolution than resist $D$. Resist $C$ exhibited a 25-nm-hp resolution without a pattern collapse and partially resolved $20 \mathrm{~nm} \mathrm{hp}$ at an exposure dose of $36 \mu \mathrm{C} / \mathrm{cm}^{2}$. It is considered that a uniform deprotection reaction of resist $\mathrm{C}$ in the exposed area, which occurred by just one series of a deprotection group could enhance the resolution limit. ZEP520A exhibited around a 25-nm-hp resolution at a dose of $88 \mu \mathrm{C} / \mathrm{cm}^{2}$. Figure 14 shows a comparison of the LER of each resist sample obtained by EB lithography. Molecular resists of resists $B$ and $C$ showed better LER than resist $D$ for 100 and $50 \mathrm{~nm} \mathrm{hp} \mathrm{patterns.} \mathrm{Resist} C$ showed better LER than resist $\mathrm{B}$, which is similar to that of ZEP520A. It is considered that a uniform deprotection and smaller variations of dissolution rates to the developer of resist $\mathrm{C}$ at the boundary between an exposed and an unexposed region by just one deprotection improves LER as well as the resolution limit. 


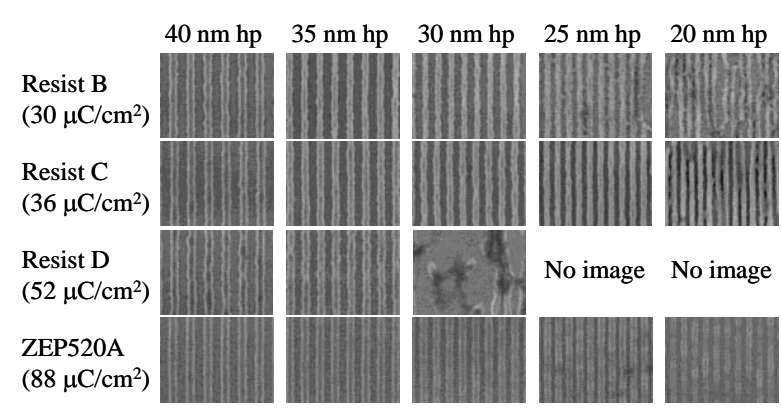

Fig. 13. Resolution comparison using EB exposure tool

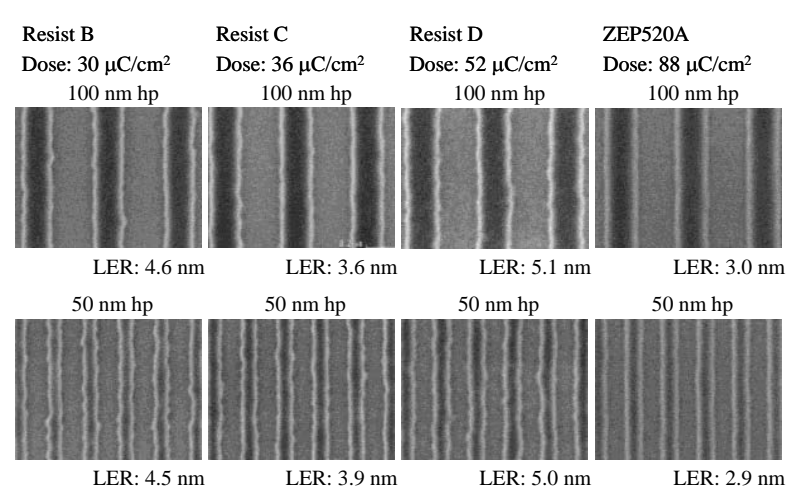

Fig. 14. LER comparison utilizing an EB exposure tool

\section{Conclusions}

Molecular resist C showed a 25-nm-hp resolution without a pattern collapse and partially resolved $20 \mathrm{~nm} \mathrm{hp}$ at an exposure dose of 36 $\mu \mathrm{C} / \mathrm{cm}^{2}$ utilizing an EB exposure tool. The LER of resist $\mathrm{C}$ was $3.6 \mathrm{~nm}$ for $100 \mathrm{~nm}$ hp line-and-space, which is similar to that of ZEP520A which is a non chemically amplified resist.

The reaction of molecular resists at the exposed area was analyzed. It was found that resist film thickness during development process was determined by a deprotection reaction ratio. It was found that the LER could be caused by the existence of different dissolution rate of the protection and the protection groups at the boundary between an exposed and an unexposed region. It is considered that a uniform deprotection reaction in the exposed area, which will lead to uniform dissolution rate of resist film improves both the LER and the resolution.

\section{Acknowledgements}

The authors would like to thank Mr. M. Iwasa of SII NanoTechnology for analyzing thermal property of resist films utilizing thermal controllable SPM.

\section{References}

1. ITRS Roadmap [http://www.itrs.net].

2. M. Yoshiiwa, H. Kageyama, Y. Shirota, F. Wakaya, K. Gamo., Appl. Phys. Lett. 69 (1996) 2605.

3. S. Hattori, S. Saito, K. Asakawa, T. Koshiba, T. Nakasugi., Proc, SPIE $\mathbf{6 9 2 3}$ (2008) 69230J.

4. S. Tanaka, M. Murakami, K. Fukushima, N. Kawano, Y. Uenoyama, K. Ito, H. Ohno, N. Matsumoto., Proc, SPIE 7273 (2009) 72732M.

5. K. Okuyama., Proc, SPIE $\mathbf{7 2 7 3}$ (2009) 72732 U.

6. T. Nishikubo, H. Kudo, Y. Suyama, H. Oizumi, T. Itani., J. Photopolym. Sci. Technol., 22 (2009) 73.

7. H. Kudo, D. Watanabe, T. Nishikubo, K. Maruyama, D. Shimizu, T. Kai, T. Shimokawa, C. K. Ober., J. Mater. Chem. 18 (2008) 3588.

8. R. A. Lawson, L. M. Tolbert, C.L. Henderson., Proc, SPIE 7273 (2009) 72733C.

9. J.-B. Kim, H.-J. Yun, Y.-G. Kwon., Chem. Lett. 10 (2002) 1064.

10. A. D. Silva, N. Felix, D. Forman, J. Sha, C.K. Ober., Proc, SPIE 6923 (2008) 692300.

11. M. Toriumi, K. Kaneyama, S. Kobayashi, T. Itani., Proc, SPIE 6923 (2008) 69230L.

12. T. Hirayama, D. Shiono, H. Hada, J. Onodera, M. Ueda., J. Photopolym. Sci. Technol., 17 (2004) 435.

13. D. Shiono, H. Hada, H. Yukawa, H. Oizumi, I. Nishiyama, K. Kojima, H. Fukuda., Proc, SPIE 6519 (2007) 65193U.

14. K. Kojima, S. Mori, D. Shiono, H. Hada, J. Onodera., J. Photopolym. Sci. Technol., 20 (2007) 429.

15. T. Owada, A. Yomogita, T. Kashiwamura, T. Kusada, S. Miyamoto, T. Takeya., Proc, SPIE 7273 (2009) 72732R.

16. M. Echigo, D. Oguro., Proc, SPIE 7273 (2009) 72732Q.

17. S. Masuda, S. Tarutani, S, Kamimura, S. Hirano, W, Hoshino, K. Mizutani., J. Photopolym. Sci. Technol., 20 (2007) 437.

18. T. Kozawa, S. Tagawa., J.Vac. Sci. Technol. B 25 (2007) 2295.

19. D. Shiono, T. Dazai, T. Hirayama, K. Kasai, H. Hada., Japan Patent 112777 (2007).

20. J. Iwashita, T. Mimura, T. Hirayama, T. Iwai., Proc, SPIE 7273 (2009) 72730. 